\title{
THE CUTANEOUS AFFECTIONS OF THE INEBRIATE.
}

\author{
By G, NORMAN MEACHEN, M.D., B.S., M.R.C.P., \\ Physician for Diseases of the Skin, Tottenham Hospital; Assistant in the \\ Skin Department, West London Hospital.
}

THE effect of continuous irritation or stimulation of an organ or tissue of the body by prolonged indulgence in any one of the intoxicants or stimulants in common use is sooner or later followed by some derangement of its function, which may, unless the cause be removed, proceed towards actual disease. The skin forms no exception to this general rule. Regarded as a composite structure, made up of glands, epithelium cells, bloodvessels, nerves, and hair, it may justly claim to be called an organ, especially as it shares with the kidneys and lungs the work of excretion; while, considered only as a cellular covering to more important parts beneath, we might look upon it simply as one of the tissues of the body. Whichever view we choose to take, one thing is clear, namely, that the cutaneous system is as injuriously affected by inebriety in any shape or form as are the other systems of the human body. The search-light of modern science has revealed, and is yet discovering, the terrible mischief and havoc wrought by alcohol, for instance, upon the liver and the nervous system. If the changes produced by the action of this destructive agent do not in the case of the skin directly endanger life, they are none the less obvious, and, moreover, they have the advantage or disadvantage of being more readily perceived and appreciated, not only by the victim himself, but also by his friends. For these reasons, perhaps, this aspect of the subject has received a smaller share of attention than it would otherwise have done. Another fact of even greater significance is that cutaneous disorders resulting from any form of intemperance are something more than "skin-deep"-in other words, they are 
frequently associated with, and may indicate the presence of, disease in the internal organs. This is not, of course, invariably the case, but the importance of the condition of the skin as an index to the general health should be more often borne in mind.

Chronic indulgence in alcohol, the most common form of inebriety, is responsible for a great number of cutaneous affections, and, as this fact is pretty widely known, many people thus afflicted are often erroneously supposed to be addicted to intemperate habits when they are in reality perfectly innocent. Hebra himself pointed out the necessity for caution before rushing to the conclusion that a skin affection is due to alcoholism. Through the kindness of the medical superintendents of many of the inebriate homes and institutions scattered throughout the country, I am enabled to state that the commonest cutaneous lesion met with in the alcohol inebriate is that form of facial erythema which goes by the name of rosacea, or, as it used to be termed, acne rosacea. This is in entire accordance with one's own experience in the skin departments of general and special hospitals, where chronic alcoholism only too often forms the basis, not only for skin troubles, but also for many visceral and nervous disorders. The affection is seen in varying degrees. In some cases-the early ones-there may be nothing more than a slight, permanent flushing about the nose and adjacent parts of the cheeks, forming a symmetrical area sometimes likened to a butterfly with outspread wings. This vascular congestion, accompanied as it frequently is by acne-like papules which may proceed towards pustulation, is produced in a twofold manner : firstly, as a direct result of the action of alcohol in dilating the peripheral bloodvessels; and secondly, through a reflex congestion of the facial capillaries, owing to the effect of the drug upon the gastric mucous membrane. Later, small protuberances or excrescences may develop, upon and around which the dilated venules may be well marked, and the condition known as rhinophyma may ultimately supervene. The largest tubercles are generally seen in wine-drinkers, according to Hebra, whereas in those who consume beer the nose is less red, more cdematous, and bloated. These changes are principally due to a condition of chronic overgrowth or hypertrophy of the cutaneous tissues as a result of the increased blood-supply to the parts, and they are very similar to those met with in other organs consequent upon long-continued habits of 
intemperance. A certain amount of dyspepsia is an almost invariable accompaniment of rosacea ; neither is this to be wondered at, considering the state of the mucous membrane of the stomach. When the epithelial cells of the skin have become permanently disorganized, as in the advanced stages of the affection, it is, of course, more difficult to restore them to their pristine condition; but, provided the exciting cause be removed, much can be done to renovate the marred complexion and to bring back once more those signs of health and beauty which Nature intended the human countenance to exhibit.

Next in order of frequency is eczema, to which, in one or other of its many forms, the alcohol-inebriate seems especially liable. This cutaneous affection is often dependent upon hereditary influences. It is also very common in gouty individuals, as well as in those who have to deal with alcoholic liquors in their daily occupation. A patch of chronic eczema, which at the best of times is rather a troublesome thing to get rid of, is far more likely to remain stationary and to assume an obstinate character when the surrounding tissues are surcharged with blood from an overfulness of the vessels than under normal conditions of nutrition. In addition to the physiological action of alcohol on the skin, the effect of the sugar and extractives contained in wines and malt liquors must also be borne in mind. Too much sweet food is generally prejudicial in eczematous affections, so that there is more than one factor at work in the production of this disease. The natural processes of repair and absorption are hindered by alcohol, so that, again, the cure of an eczema under these circumstances is apt to be slow.

That oxidation throughout the tissues of the body is greatly diminished by alcohol has been abundantly proved by the latest scientific researches. We can, therefore, readily understand that " the skin of the alcoholic becomes flabby, readily soaked, and permeable. There is an imperfect combustion of fat, which accumulates in the tissues, especially in the integument, imparting to it a velvety softness, almost pathognomonic of potatory habits." These words of Sir Lauder Brunton express most accurately a condition of skin commonly seen in the alcoholinebriate. The sweat-glands, which lie in the deeper layers of the skin, are sometimes stimulated to greater action, probably through the direct influence of the nervous system upon the 
bloodvessels which supply them. They are very numerous in the palms of the hands, where their increased secretion is often a source of great annoyance to the unfortunate sufferer therefrom. Other causes besides alcohol may be productive of this distressing complaint, which is known as hyperidrosis.

There is one symptom which is common to a great many cutaneous diseases, and that is pruvitus, or itching. Its exact mechanism is somewhat complex, but there can be little doubt that it is produced by the irritation of the nerve-endings in the epidermis, whether from without, as in the case of a foreign body, or from within, when the itching is due to the circulation of some toxic substance in the blood-stream. Alcohol acts in the latter way. All inflammatory affections of the skin, especially if they are accompanied by itching, are aggravated by indulgence in alcoholic liquors. In a similar manner those cutaneous disorders which manifest themselves by eruptions resembling "nettle-rash," comprising the large group of erythematous and urticarial diseases, are banefully influenced by intemperate habits. The vaso-motor nervous system is the one which suffers most, and when the control over the blood-supply is impaired by the toxic action of alcohol upon the nerves themselves, these rashes are not only liable to appear upon very slight provocation, but are apt to show an extraordinary degree of persistence and chronicity. A special form of cutaneous irritation has been observed in absinthedrinkers by Gastou, in which irregularly distributed patches of anæsthesia are found in different parts of the body, preceded by intense itching. This ancesthetic pruvigo is generally worse at night, in common with nearly all varieties of itching, and is sometimes so pronounced as to constitute a valuable sign of chronic alcoholism.

By lowering the resistance of the skin to infection, alcohol is an important predisposing cause of scrofulous disorders, such as lupus and other tubercular diseases; while it also permits a surer foothold to septic micro-organisms, should these find a restingplace in the cutaneous tissues. Thus, boils and carbuncles do badly in alcoholic subjects. The phagocytic power of the white bloodcorpuscles is also diminished, so that absorption and destruction of septic material is less easily accomplished. Varicose and other ulcers of the leg make very slow progress towards recovery in those 
whose systems are permeated through and through with the drug.

Turning now to other forms of inebriety, we find that the cutaneous system is affected considerably by certain beverages, which, when taken to excess, produce quite as definite, though not so deadly, effects upon the bodily tissues. So frail is the human heart, that, even while priding itself upon its power to abstain from alcohol, it must needs lean upon some other material prop, in the shape of tea or coffee. But though these substances are not quite the broken reed that alcohol is, yet their sustaining powers fail signally when put to a practical test. Both are enormously and increasingly consumed by the masses of to-day, and as the symptoms of excess are far less obvious than those of alcohol, the limit beyond which an increased quantity is positively injurious is overstepped more easily. Coldness of the hands and feet is sometimes produced and nearly always aggravated by much tea-drinking. Chronic tea-intoxication manifests itself by an increased nervousness and excitability, together with an irregular action of the heart. Inasmuch as it produces a state of chronic dyspepsia when made badly, it intensifies, like alcohol, any erythematous condition about the face, such as rosacea. Professional tea-tasters do not, as a rule, swallow much, if any, of the beverage; but in some cases of actual tea-poisoning occurring among them a general shrinking or shrivelling up of the skin with abnormal dryness of the surface has been noticed.

The influence of coffee upon the skin is more definite. It was Brown-Séquard and Thursfield who considered that coffee might be responsible for a severe pruritus, as they observed distinct relief follow upon its removal from the dietary. Many cases have been recorded in which ointments and lotions were tried without benefit, but as soon as coffee was withdrawn the itching ceased. The minute amount of aromatic oil contained in coffee seems to be the irritating material which, circulating in the bloodvessels, stimulates the sensory nerve-endings in such an unpleasant manner. Perfetti states that the two chief morbid cutaneous phenomena resulting from the abuse of coffee are (I) pruritus, and (2) secondary, polymorphous eruptions due to scratching. Both of these may vary according to the susceptibility of the individual to the coffee-intoxication. M. Brocq considers that there is a special cutaneous reaction for coffee, and 
he points out that the daily absorption of large quantities of the beverage bears a direct relationship to certain forms of itching of the skin.

Ether-taking, though not common, is nevertheless a form of inebriety which seems to offer special attractions to its unfortunate victims. Dr. Walter Bernard (quoted by the late Mr. Ernest Hart) states that among the injurious effects produced by this vice are "absence of subcutaneous fat, muscular wasting, feeble circulation, pale lemon and brown coloured skin."

Cutaneous effects are frequently seen in chronic opium-poisoning and morphinomania. The itching produced by opium is well known, though the action of the drug in this respect is less obvious, owing to the mental disturbances which speedily ensue. An agreeable, general itching often follows a fresh injection in chronic morphia-takers. The skin may also become harsh, dry, and of a sallow tint, while the hair falls out and the nails become brittle. The loss of hair is usually coincident with the decay of the teeth, a symptom which, as a rule, is well marked. The scars inflicted by the morphia-syringe may themselves be attacked by morbid processes. A curious case of this description was shown by M. Rille before the Viennese Society of Dermatology in 1898 , in a lady, aged forty-two, who had been addicted to the morphia habit for eighteen years. Her skin presented a most extraordinary appearance, the surface of the limbs being covered with small nodosities, varying in size from a pea to that of a walnut, corresponding to the punctures of the hypodermic needle with which she used to introduce the drug into her system. A condition of hypertrophic scar, or keloid, may follow the puncture of a needle in the same way as it may ensue in the scar left by a clean-cut incision with a knife.

There is another form of inebriety in which cutaneous signs are often prominent-namely, that due to cocaine. Sometimes those who indulge in the use of cocaine do not show outwardly anything abnormal, but it is more frequent to find that cocaine habitués appear emaciated, with pinched features, pale and yellowish skin, clammy extremities, and cold perspiration. One symptom of chronic cocaine-intoxication is noteworthy. This is known as Magnan's sign, having been described by that observer in 1889. It consists of a hallucination of a increased cutaneous 
sensibility, so that the patient believes that there is actually some foreign body present beneath the skin. Springthorpe states that, " after a relatively short time, the cocainist begins the hunting of the cocaine-bug, and imagines that in his skin worms or similar things are moving along."

Other eruptions upon the skin or alterations in its sensibility appear in those who are addicted to various drug habits. The pernicious practice of indiscriminate self-dosing with certain drugs for the relief of neuralgia or insomnia is one of the greatest evils of modern society. Bromide of potassium, chloral hydrate, and antipyrin are among the most common nostrums which are taken in this manner. Erythematous and papular eruptions are not unfrequently seen in individuals who give way to this form of intemperance.

We thus see that the different cutaneous affections met with among the inebriate are both numerous and widespread. Even though they seldom or never threaten life, yet many of them cause enough suffering to demand our careful attention; while their occurrence affords undeniable proof of the mischief which the intoxicating agent, whatever it may be, is subtly but surely working in the system of its chain-bound victim.

\footnotetext{
"We would have health, and yet Still use our bodies ill."
}

If cutaneous health be desired-and from its ready visibility it is ever sought for and assiduously cherished by the majority of people-we as a nation and as individuals must see to it that the yoke and tyranny of such bad masters as the various intoxicating and narcotic drugs have proved themselves to be shall be removed from those who groan under their burden.

\section{REFERENCES.}

Broce: La Presse Méd., May 2, 1903.

Meachen: Med. Temp. Rev., June, 1903.

Perfetia: Thèse de Paris, Igoz.

Rille: Annales de Derm., 1898.

SPRINGTHORPE: Quart. Journ. of Inebriety, January, 1897 . 